\title{
Características das vítimas de picada de animais peçonhentos notificadas em Lorena-SP/2006
}

\author{
Kellen Cristiane Espíndola Pires*, Marina Andressa Seraphim*, Fabiola Vieira Cunha**
}

${ }^{*}$ Discente das Faculdades Integradas Teresa D'Ávila (FATEA), ${ }^{*}$ Enfermeira, Especialista em Traumatologia e Emergência, Mestranda em Enfermagem - Acidente de trânsito / Causas Externas na Universidade de Guarulhos/ Docente das Faculdades Integradas Teresa D'Ávila (FATEA)

\begin{abstract}
Resumo
Trata-se de um estudo descritivo e quantitativo, realizado através das fichas de notificação compulsória. O objetivo do estudo foi mostrar os tipos de acidentes ocorridos com animais peçonhentos: escorpiáo, aranha e serpente, notificados na cidade de Lorena-SP no período de 2006. Foram identificados 46 casos notificados, sendo 50\% (23) vítimas de escorpiáo; 26\% (12) de aranha e $22 \%$ de serpente (10) e analisadas as características relacionadas às vítimas: verificou-se que o maior índice de casos era do gênero masculino 65\% (30), a prevalência dos acidentes ocorreu na zona urbana com 48\% (22 casos) e o mês com maior número de casos notificados foi dezembro com $23,9 \%$ (11 casos). Conclui-se que é importante a sistematização do atendimento para evitar que pontos importantes sejam esquecidos e, além de facilitar, tornar a assistência mais ágil e efetiva.
\end{abstract}

Palavras-chave: acidentes, animais peçonhentos, picadas de animais.

\section{Abstract \\ Characteristics of notified victims of venomous animals bite or stung in Lorena-SP/ 2006 \\ It is a descriptive and quantitative study that was carried out through entrance form notice. It aimed at showing the kind of accidents occurred with venomous animals: scorpion, spider and serpent, which were notified in Lorena city - SP in 2006. Of the 46 notified cases, $50 \%$ ( 23 cases) were victims of scorpion sting; $26 \%$ (12 cases) of spider bite and $22 \%$ of snakebite (10 cases). It was also analyzed victims characteristics: male cases are higher than women $65 \%$ (30 cases); prevalence of accidents occurred in the urban zone with 48\% (22 cases); and December was the most notified month with $23,9 \%$ (11 cases). It was concluded the importance of care systematization, in order to highlight important points that should not be forgotten and, moreover, to make the assistance easier, faster and more effective.}

Key-words: accidents, venomous animals, animals bite. 


\section{Resumen \\ Características de las víctimas de mordedura y picadura de animales venenosos notificados en Lorena-SP/2006}

Se trata de un estudio descriptivo y cuantitativo, realizado a través de las fichas de notificación obligatoria. El objetivo de estudio fue demostrar los tipos de accidentes con animales venenosos: escorpión, arańa y serpiente, notificados en la ciudad de Lorena - SP en el año de 2006. Fueron identificados 46 casos notificados, de los cuales 50\% (23 casos) víctimas de picadura de escorpión; $26 \%$ (12 casos) de picadura de arańa y $22 \%$ de mordedura de serpiente (10 casos) y, además, fueron analizadas las características relacionadas con las víctimas: se verificó que el mayor índice de víctimas era del género masculino 65\% (30 casos), la prevalencia de los accidentes ocurrió en zonas urbanas con 48\% (22 casos) y el mes con el mayor número de casos notificados fue Diciembre con 23,9\% (11 casos). Se concluye que es muy importante la sistematización de la asistencia, de manera que aspectos importantes no se olviden y, también facilitar, para que la asistencia sea más ágil y eficaz.

Palabras-clave: accidentes, animales venenosos, picaduras de animales.

\section{Introdução}

Os acidentes provocados por animais têm grande importância médica no país, principalmente pelo grande número de pessoas vitimadas e pela sua gravidade [1].

Os animais peçonhentos possuem glândulas de veneno que se comunicam com dentes ocos, ferróes ou aguilhóes inoculadores do veneno, por exemplo: serpentes, aranhas, escorpiōes, abelhas, arraias etc. [2]. Os venenosos possuem o veneno, todavia, não tem um aparelho inoculador (dentes, ferróes). Provocam envenenamento por contato (lagartas), por compressão (sapo) ou por ingestáo (peixe-baiacu) [2].

$\mathrm{O}$ acidente por animal peçonhento sempre é mais grave na criança, conseqüentemente as seqüelas e a mortalidade são mais altas. Por isso, o atendimento precoce através da soroterapia é de grande importância [3].

Os acidentes causados por serpentes peçonhentas representam significativo problema de saúde pública, especialmente em países tropicais, pela freqüência com que ocorrem e pela morbimortalidade que ocasionam [4]. No Brasil, as serpentes peçonhentas pertencem a quatro gêneros: Bothrops, Crotalus, Lachesis e Micrurus. Estudo realizado por Ribeiro [5] identifica que os acidentes por serpentes, no Estado de Sáo Paulo, são provocados por Bothrops, Crotalus e Micrurus.

Com relação aos acidentes provocados por escorpiáo, no Brasil, estima-se que ocorram cerca de 8.000 acidentes/ano, representando uma incidência anual aproximada de 3 casos/100.000 habitantes, estando 50\% deles restritos aos estados de Minas Gerais e São Paulo [6].

Dentre os acidentes por animais peçonhentos, os causados por aracnídeos são de relevância clínica, tanto pelas freqüências, quanto pelas complicaçóes que podem advir se não forem adequadamente tratados. Os mais sérios, relatados em humanos, ocorrem com o gênero Phoneutria, relativamente comuns nas regióes sudeste e sul do Brasil [7].

O objetivo desta pesquisa foi avaliar e identificar os tipos de acidentes ocorridos com animais peçonhentos: escorpião, aranha e serpente, atendidos na cidade de Lorena - SP no período de 2006; identificar as características das vítimas quanto: à idade; ao sexo; ao local do acidente (zona urbana ou zona rural); ao local de procedência da vítima; à circunstância do acidente (trabalho ou lazer); ao local da picada; ao soro utilizado; ao tempo ocorrido do acidente até o atendimento das vítimas; ao número de casos no total e, finalmente, a análise do preenchimento das fichas de notificação compulsória.

\section{Material e métodos}

Trata-se de um estudo do tipo descritivo, com abordagem quantitativa, realizado na Secretaria Municipal de Saúde, no departamento da Vigilância Epidemiológico da cidade de Lorena, no interior do estado de São Paulo, situada no Vale do Paraíba, através de pesquisa direta em fichas epidemiológicas de notificaçóes de acidentes por animais peçonhentos na Secretaria de Saúde no Departamento da Vigilância Epidemiológica da cidade de Lorena - SP relativas ao período de 2006. 
Foram avaliados os níveis estatísticos em relação ao instrumento de coleta de dados que possui a identificação quanto à idade que é relacionada a cada cinco anos; ao gênero; ao município em que reside, para determinar a origem da vítima; ao local de procedência, para determinar o município de ocorrência do acidente; ao local do acidente, para definir zona rural ou urbana; à circunstância do acidente - atividade desenvolvida pela vítima no ato da picada -; ao local da picada, para levantar o índice da regiáo anatômica mais acometida; ao tipo de animal, para determinar a espécie do animal peçonhento; ao soro utilizado para identificar o tipo de animal que causou o acidente e ao tratamento realizado; ao tempo ocorrido do acidente até o atendimento da vítima e o mês de notificação para analisar os meses que apresentaram maior índice de casos.

\section{Resultados}

Foram avaliadas 46 fichas de notificação compulsória de acidentes de animais peçonhentos, no período de 2006, na cidade de Lorena - SP e analisados os dados dos acidentes ocorridos para os tipos de animais: escorpiáo, aranha e serpente.

$\mathrm{O}$ animal peçonhento que teve maior índice de acidentes, neste estudo, foi o escorpião com 23 casos $(50 \%)$, seguido da aranha com 12 casos $(26 \%)$ e 10 casos $(22 \%)$ por serpentes.

O município de Lorena - SP notificou 18 casos de picadas de escorpiáo (39\%), dos quais 10 pessoas do gênero masculino (22\%) e 7 do feminino $(15,2 \%)$; o local de ocorrência foi a zona urbana com 12 casos $(26 \%)$ e zona rural 5 casos $(10,9 \%)$; as circunstâncias do acidente ocorreram em outros 8 casos náo especificados $(17,4 \%)$, durante o trabalho 5 casos $(10,9 \%)$ e lazer 4 casos $(8,7 \%)$; a média de intervalo de tempo do acidente com escorpião até o atendimento foram 8 casos entre 0 a $1 \mathrm{~h}(17,4 \%), 4$ casos entre 1 a 3 horas $(8,7 \%)$ e 4 casos ignorados (8,7\%); local da picada mais acometido foi a região da mão com 6 casos (13\%); as faixas etárias de acordo o número de casos por escorpiāo foram de 11 a 15 anos, 21 a 25 anos, 36 a 40 anos com 3 casos cada $(6,5 \%)$ e o mês com maior índice foi dezembro que foram notificados 6 casos (13\%), uso de soro em 16 casos $(34,7 \%)$ não foram utilizados, em 2 casos (4,3\%) foram utilizados outros medicamentos (dipirona $E V e$ fernegam $I M)$ e 1 caso $(2,2 \%)$ utilizou 2 ampolas de soro antiescorpiônico.
As vítimas de picadas em Cachoeira Paulista SP foram atendidas na cidade de Lorena - SP devido a ser referência e possuir o soro caso necessário, ocorreram 3 casos de escorpião (6,5\%). Os casos envolvendo picadas de escorpiáo atingiram somente pessoas do gênero masculino com 3 casos $(6,5 \%)$; o local de maior ocorrência foi à zona urbana 2 casos $(4,3 \%)$, local ignorado 1 caso $(2,2 \%)$ e nenhum caso na zona rural; as circunstâncias do acidente ocorreram em outros 2 casos não especificados (4,3\%) e 1 caso onde o local foi ignorado (2,2\%); as médias de intervalo de tempo do acidente com escorpiáo até o atendimento foram 1 caso de 0 a $1 \mathrm{~h}, 3$ a 6 h e 6 h a 12 h cada $(2,2 \%)$; locais da picada mais acometidos foram as regiōes da cabeça, braço e dedo da mão com 1 caso cada (2,2\%); as faixas etárias de acordo com o número de casos por escorpião foram 26 a 30 anos, 36 a 40 anos e mais de 61 anos com 1 caso cada $(2,2 \%)$ e os meses com maiores índices foram setembro, outubro e dezembro com 1 caso cada $(2,2 \%)$; uso de soro 1 caso $(2,2 \%)$ náo foi utilizado, em $2(4,3 \%)$ casos foram utilizados soro antiescorpiônico, 1 caso administrou 2 ampolas de soro e outro náo foi especificada a quantidade de ampolas.

As vítimas da cidade de Canas - SP foram atendidas também na cidade de Lorena e ocorreram 2 casos de escorpião (4,3\%): uma do gênero masculino e uma do feminino (2,2\%); o local de ocorrência foi à zona rural 1 caso $(2,2 \%)$ e com 1 caso ignorado $(2,2)$; as circunstâncias do acidente ocorreram durante o lazer 2 casos (4,3\%); as médias de intervalo de tempo do acidente com escorpiáo até $\mathrm{o}$ atendimento foram 1 caso de 0 a $1 \mathrm{~h}$ e $1 \mathrm{~h}$ a 3 h cada (2,2\%); locais da picada mais acometidos foram às regióes da mão e coxa com 1 caso cada $(2,2 \%)$; as faixas etárias de acordo com o número de casos foram de 0 a 5 anos e 11 a 15 anos com 1 caso cada $(2,2 \%)$ e os meses com maiores índices foram outubro e novembro com 1 caso cada (2,2\%), em 1 caso $(2,2 \%)$ não foi utilizado soro, e 1 caso $(2,2 \%)$ utilizou 4 ampolas de soro antiescorpiônico.

No município de Piquete - SP náo aconteceu nenhum caso registrado de acidente com escorpião.

$\mathrm{Na}$ cidade de Lorena ocorreram 7 casos de acidentes com aranhas $(15,2 \%)$, dos quais 4 pessoas do gênero feminino $(8,7 \%), 2$ do gênero masculino $(4,3 \%)$ e 1 caso ignorado (2,2\%); o local de maior ocorrência foi à zona urbana 6 casos $(13 \%)$ e zona rural 1 caso $(2,2 \%)$; as circunstâncias do acidente 
ocorreram durante o lazer 4 casos $(8,7 \%)$, trabalho 2 casos $(4,3 \%)$ e 1 caso ignorado (2,2\%) e as médias de intervalo de tempo do acidente com aranha até o atendimento foram de 3 casos de 0 a $1 \mathrm{~h}$ (6,5\%), 2 casos de $1 \mathrm{~h}$ a $3 \mathrm{~h}(4,3 \%)$ e 2 casos ignorados $(4,3 \%)$; locais da picada mais acometidos foram a regiáo do pescoço com 2 casos (4,3\%), braço, dedo da mão, pé e dedo do pé com 1 caso cada $(2,2 \%)$ e 1 local da picada foi ignorado (2,2\%); faixas etárias de acordo com o número de casos de acidente por aranha foram de 26 a 30 anos e mais de 61 anos com 2 casos cada (4,3\%), 46 a 50 anos e até 60 anos com 1 caso cada $(2,2 \%)$ e 1 caso com a faixa etária ignorada $(2,2 \%)$ e os meses com maiores índices foram dezembro notificou 3 casos $(6,5 \%)$, abril, julho, agosto, outubro com 1 caso cada $(2,2 \%) ; 6$ casos $(13 \%)$ não utilizou soro, 1 caso $(2,2 \%)$ utilizou 4 ampolas de soro antiaracnídico e 1 caso realizou apenas exames laboratoriais.

As vítimas de picadas por aranhas em Cachoeira Paulista - SP foram atendidas na cidade de Lorena devido a ser referência e possuir o soro caso necessário, ocorreram 2 casos de aranha (4,3\%): 1 pessoa do gênero masculino $(2,2 \%)$ e 1 caso ignorado $(2,2 \%)$; o local de maior ocorrência foi a zona rural 1 caso $(2,2 \%)$ e 1 caso ignorado (2,2\%); as circunstâncias do acidente ocorreram em 1 caso não especificado $(2,2 \%)$ e 1 caso de lugar não especificado $(2,2 \%)$; a média de intervalo de tempo do acidente com aranha até o atendimento foi 1 caso de $1 \mathrm{~h}$ a $3 \mathrm{~h}(2,2 \%)$ e 1 caso ignorado $(2,2 \%)$; local da picada mais acometido foi a regiáo da mão e do pé com 1 caso cada (2,2\%); faixas etárias de acordo com o número de casos foram de 0 a 5 anos e 21 a 25 anos com 1 caso cada (2,2\%) e os meses com maior índice foram março e maio com 1 caso cada $(2,2 \%)$; 1 caso $(2,2 \%)$ utilizou soro, e 1 caso $(2,2 \%)$ utilizou 4 ampolas de soro antiaracnídico mais fernegam IM, dipirona IM e dexametasona $1,0 \mathrm{ml}$.

As vítimas de picadas de aranha da cidade de Canas - SP, 2 casos (4,3\%) foram atendidas na cidade de Lorena, sendo que 1 pessoa era do gênero masculino e outra do feminino $(2,2 \%)$; o local de maior ocorrência foi à zona urbana e zona rural 1 caso cada $(2,2 \%)$; as circunstâncias do acidente ocorreram 1 caso durante o lazer (2,2\%) e 1 caso ignorado (2,2\%); a média de intervalo de tempo do acidente com aranha até o atendimento foram 2 casos de 1 h a 3 h $(4,3 \%)$; local da picada mais acometido foi a região do pé com 2 casos $(4,3 \%)$; faixas etárias de acordo com o número de casos por aranha foram de 0 a 5 anos e 11 a 15 anos com 1 caso cada $(2,2 \%)$ e o mês com maior índice foi maio no qual foram notificados 2 casos (4,3\%); nos 2 casos $(4,3 \%)$ não foi utilizado soro.

No município de Piquete - SP ocorreu apenas 1 caso de picada de aranha do gênero feminino $(2,2 \%)$; o local de ocorrência, a circunstância do acidente e o local da picada foram ignorados; a média de intervalo de tempo do acidente com aranha até o atendimento foi 1 caso ignorado (2,2\%); a faixa etária foi de 26 a 30 anos e o mês que foi notificado $o$ acidente foi maio; nenhum soro foi utilizado.

Em Lorena ocorreram 4 casos de picadas de serpentes. Os casos envolvendo picadas de serpentes atingiram 4 pessoas do gênero masculino $(8,7 \%)$; o local de maior ocorrência foi a zona rural 3 casos (6,5\%) e 1 caso ignorado (2,2\%); as circunstâncias do acidente ocorreram durante o trabalho 2 casos $(4,3 \%)$, lazer 1 caso $(2,2 \%)$ e 1 caso ignorado (2,2\%); as médias de intervalo de tempo do acidente com serpente foram de 2 casos de 1 a $3 \mathrm{~h}(4,3 \%)$, 1 caso de 0 a 1 h $(2,2 \%)$ e 1 hora ignorada (2,2\%); locais da picada mais acometidos foram a regiáo do pé com 3 casos $(6,5 \%)$ e 1 na região da perna (2,2\%); as faixas etárias de acordo com o número de casos por serpentes foram de 41 a 45 anos com 2 casos (4,3\%), 46 a 50 e até 60 anos com 1 caso cada $(2,2 \%)$ e os meses com maiores índices foram março, abril, outubro e um mês ignorado com 1 caso cada (2,2\%); uso de soro em 4 casos (8,7\%), 1 caso utilizou 5 ampolas de soro antibotrópico e 3 casos utilizaram 10 ampolas de soro antibotrópico cada.

As vítimas de picadas em Cachoeira Paulista - SP foram atendidas na cidade de Lorena - SP. Os casos envolvendo picadas de serpentes atingiram 4 pessoas do gênero masculino (8,7\%); o local de maior ocorrência foi a zona rural com 3 casos $(6,5 \%)$ e 1 caso na zona urbana (2,2\%); as circunstâncias do acidente ocorreram durante o trabalho 3 casos $(6,5 \%)$ e lazer 1 caso $(2,2 \%)$; a média de intervalo de tempo do acidente com serpente foram 1 de 0 a 1 h, 1 a 3 h, 3 a 6 h e 6 a 12 h cada (2,2\%); locais da picada mais acometidos foram a regiáo da perna com 2 casos (4,3\%), 1 caso na regiáo do dedo do pé e 1 local da picada ignorado (2,2\%); faixas etárias de acordo com o número de casos por serpentes foram de 16 a 20 anos, 21 a 25 anos, 41 a 45 anos com 1 caso cada $(2,2 \%)$ e um caso ignorado a idade $(2,2 \%)$ e os meses com maior índice foram junho com 2 casos $(4,3 \%)$, janeiro e setembro apenas 1 
caso cada (2,2\%); uso de soro em 4 casos $(8,7 \%), 2$ casos utilizaram 10 ampolas de soro antibotrópico, 1 caso utilizou 5 ampolas de soro antibotrópico e 1 caso utilizou 3 ampolas de soro antibotrópico.

No município de Canas - SP não aconteceu nenhum caso registrado de acidente com serpente.

O município de Piquete - SP encaminhou as vítimas de picada de serpente também para a cidade de Lorena. Os casos envolvendo picadas de serpentes atingiram 3 pessoas do gênero masculino $(6,5 \%)$; o local de maior ocorrência foi a zona rural 3 casos (6,5\%); as circunstâncias do acidente ocorreram durante o trabalho 3 casos $(6,5 \%)$; a média de intervalo de tempo do acidente com serpente foi de 1 a 3 h 1 caso $(2,2 \%)$ e 2 casos ignorados a hora (4,3\%); o local da picada mais acometido foi a regiáo do dedo da mão com 3 casos $(6,5 \%)$; faixas etárias de acordo com o número de casos por serpentes foram de 36 a 40 anos com 1 caso $(2,2 \%)$, até 60 anos com 1 caso $(2,2 \%)$ e 1 idade ignorada $(2,2 \%)$ e os meses com maiores índices foram maio, agosto e dezembro com 1 caso cada (2,2\%); 3 casos não utilizaram soro antibotrópico, 1 caso utilizou 10 ampolas de soro antibotrópico, 1 caso utilizou 9 ampolas de soro antibotrópico e 1 caso utilizou 5 ampolas de soro antibotrópico.

A maioria dos casos de vítimas de notificaçóes compulsória de acidentes com animais peçonhentos, no período de 2006, 63\% (29 casos) ocorreu na própria cidade de Lorena, seguido por 19,6\% (9 casos) vindos da cidade de Cachoeira Paulista - SP, os municípios de Canas - SP e Piquete - SP com 8,7\% (4 casos) cada.

Em um indivíduo do gênero masculino, 42 anos, do município de Lorena-SP, acidente ocorrido na zona urbana, durante o lazer, atingindo o membro inferior na região do pé, notificado no dia $03 / 01 / 2006$, o animal foi ignorado, foram utilizadas 2 ampolas de soro antiescorpiônico. Em casos de picadas por serpentes o soro utilizado é de acordo com o gênero; acidente com escorpião é utilizado o soro antiescorpiônico (SAEsc) ou antiaracnídico (SAA); e em casos de acidente com aranha é utilizado somente o soro antiaracnídico (SAA), dados segundo orientação descrita pelo SINAN (Sistema de Informação de Agravos de Notificação) da ficha de notificação compulsória de acidentes por animais peçonhentos, do Ministério da Saúde.

A maioria das vítimas é do gênero masculino 30 casos (65,2\%), 14 casos do sexo feminino $(30,4 \%)$ e 2 casos foram ignorados (4,3\%). (Gráfico 1 )
Gráfico 1 - Porcentagem dos acidentes de animais peçonhentos, registrados pela Secretaria Municipal de Saúde, da cidade de Lorena - SP, no período de 2006, segundo o gênero.

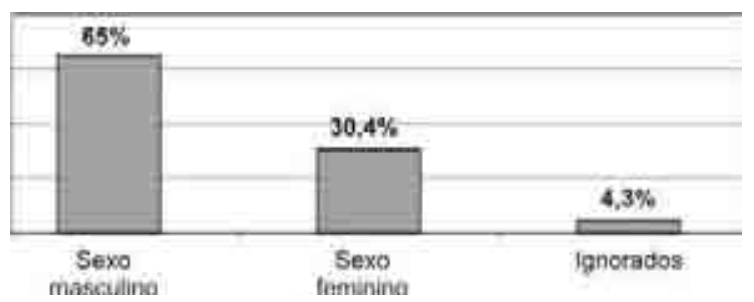

O local de maior ocorrência dos acidentes foi na zona urbana com 22 casos (48\%), zona rural com 19 casos $(41,3 \%)$ e 5 casos ignorados $(10,9 \%)$. (Gráfico 02).

Gráfico 2 - Porcentagem dos acidentes de animais peçonhentos, registrados pela Secretaria Municipal de Saúde, da cidade de Lorena - SP, no período de 2006, segundo local de ocorrência.

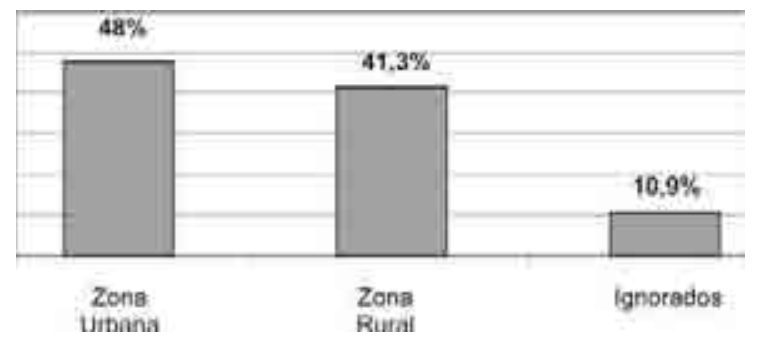

Os casos ocorridos por picada dentro de casa $17,4 \%$ (8 casos), sendo em zona urbana 13\% (6 casos) e zona rural 4,3\% (2 casos). (Gráfico 3)

Gráfico 3 - Porcentagem dos acidentes de animais peçonhentos, registrados pela Secretaria municipal de Saúde, da cidade de Lorena - SP, no período de 2006, segundo acidentes ocorridos dentro da residência.

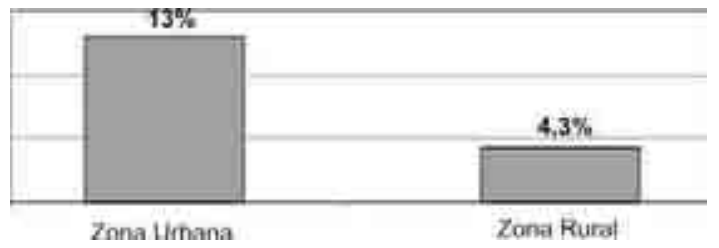

As circunstâncias do acidente durante o trabalho foram 33\% (15 casos), lazer 30,4\% (14 casos), outros $17,4 \%$ (8 casos) e 19,6\% ( 9 casos) ignorados.

$\mathrm{O}$ intervalo de tempo do acidente até o atendimento da vítima ocorreu entre 0 a $1 \mathrm{~h}$ com 15 casos (33\%), 1 a 3 h com 14 casos $(30,4 \%), 3$ a 6 h 2 casos (4,3\%), 11 casos foram ignorados o tempo $(23,9 \%), 6$ a 12 h com 4 casos $(8,7 \%)$, mais de 12 $\mathrm{h}$ não ocorreu em nenhum caso. 
Os locais da picada prevalecem índices iguais, quando analisados o membro superior e membro inferior representam 50\% (23 casos) cada, sendo a região da mão com 8 casos $(17,4 \%)$ e a região do pé com 10 casos $(22 \%)$ e 3 casos ignorados $(6,5 \%)$.

As faixas etárias mais acometidas foram de 11 a 15 anos, 21 a 25 anos, 26 a 30 anos, 36 a 40 anos e mais de 61 anos com 5 casos cada (10,9\%); de 0 a 5 anos, 41 a 45 anos e até 60 anos com 4 casos cada (8,7\%); faixa etária ignorada com 3 casos $(6,5 \%) ; 16$ a 20 anos e 46 a 50 anos com 2 casos cada (4,3\%) e de 6 a 10 anos e 31 a 35 anos apenas 1 caso de cada $(2,2 \%)$.

Os meses que apresentaram maiores números de casos foram dezembro $23,9 \%$ (11 casos), seguido pelo mês de outubro $17,4 \%$ (8 casos), a seguir os meses de maio e novembro $10,9 \%$ (5 casos); janeiro, abril, junho 4,3\% (2 casos); março, agosto, setembro 6,5\% (3 casos); julho 2,2\% (1 caso) mesmo índice de mês que foi ignorado e o mês de fevereiro não foi notificado nenhum acidente. (Gráfico 4).

\section{Discussão}

Estudos anteriores demonstram o grande índice de vítimas do gênero masculino como no estado de Goiás, onde a predominância dos acidentes por serpentes foi de vítimas do gênero masculino, totalizando 78,5\% [4]. O mesmo ocorre no estado de Sáo Paulo, o maior índice das vítimas de animais peçonhentos é do gênero masculino [8]. Em outro estudo com acidentes com ofídicos as vítimas do gênero masculino foram $77 \%$ dos casos [9].

Em relação ao tempo de atendimento, mais de $80 \%$ dos envenenamentos por acidentes com serpentes foram atendidos em menos de 6 horas após a picada [4]. Outro estudo com serpentes registrou o atendimento dentro de 3 a 6 horas após a picada, respectivamente, $73,2 \%$ e $89 \%$ dos casos [5].

Estudo com serpentes em Goiás demonstrou que a região mais acometida foi o pé com 43,6\% dos casos [4]. Ribeiro et al. [5] registraram maior freqüência de picadas de serpentes na região do pé (42,2\%).

Estudo realizado no estado da Bahia demonstrou que $92,3 \%$ dos casos de acidentes com escorpiáo ocorreram no interior dos domicílios [6]. As vítimas de escorpião foram picadas principalmente na regiáo das mãos $(41,4 \%)$ [10].

Belluomini et al. [9] chamam a atenção para os casos de acidentes de trabalho, sendo caracterizados 131 casos (11,5\%) dos casos de araneísmo. Apontam também o maior índice de acidentes vítimas de aranhas 41,2\%. No estudo de Miranda et al., observou-se que a maior prevalência dos casos de acidentes com aranhas foram em março, abril e maio. A soroterapia utilizada foi indicada em dois pacientes avaliados com acidentes por aracnídeos [7].

Nota-se que a maioria dos dados analisados no município de Lorena - SP, no período de 2006, coincide com os dados notificados dos estudos analisados e descritos acima.

\section{Conclusão}

Percebe-se com base em alguns dados que foram ignorados nas fichas de notificaçáo, que existe a falta de orientação, esclarecimento e treinamento por parte da equipe de saúde, quanto à necessidade e importância do preenchimento correto e completo dos dados solicitados, para que se tenha o conhecimento preciso e que sejam realizadas políticas de saúde pública para a prevençáo de novos casos de picadas no município.

Sugere-se para a equipe de saúde hospitalar e o Departamento da Vigilância Epidemiológica da cidade de Lorena - SP, uma implantação de programas contínuos de esclarecimento sobre riscos e medidas de prevenção promovendo mudanças comportamentais que se refletirão na redução dos índices de acidente nas cidades analisadas.

Por meio deste estudo poderemos promover políticas de prevenção para o município, através de

Gráfico 4 - Porcentagem dos acidentes de animais peçonhentos, registrados pela Secretaria municipal de Saúde, da cidade de Lorena - SP, no período de 2006, segundo mês de notificação.

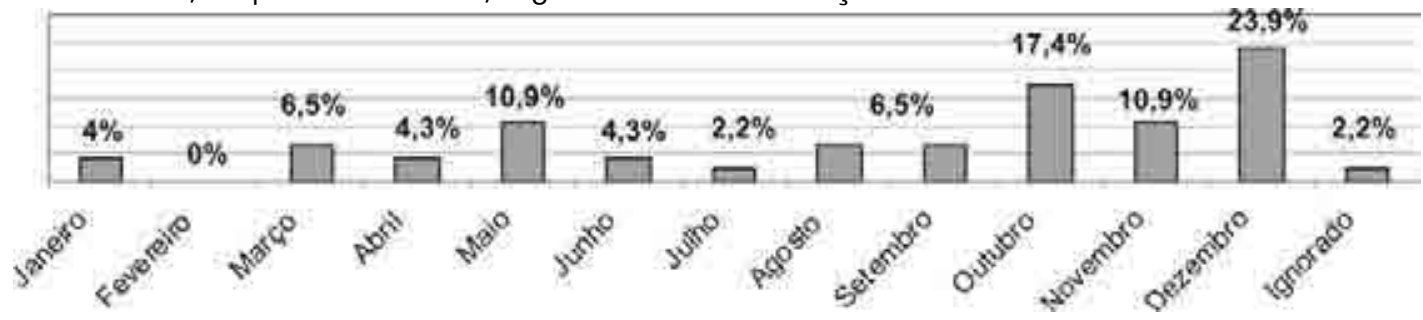


levantamento dos dados e poderá servir de base para estudos posteriores.

\section{Referências}

1. Pardal PPO, Ribeiro MB, Miranda ASP. Aspectos clínicos dos acidentes por animais.Rev Para Med 2002;16(4):26-32.

2. Secretária de Estado da Saúde do Paraná. Centro de Epidemiologia do Paraná. Centro de Informação Toxicológica de Curitiba. Prevenção de acidentes com animais peçonhentos. Cartilha. Curitiba: Secretária de Estado da Saúde do Paraná; 1997.

3. Oliveira JS, Campos JA, Costa DM. Acidentes por animais peçonhentos na infância. J Pediatr 1999;75(supl.2): S251-S258.

4. Pinho FMO, Oliveira ES, Faleiros F. Acidente ofídico no estado de Goiás. Rev Assoc Med Brás 2004;50(1): 93-96.

5. Ribeiro LA, Albuquerque MJ, Pires Campos VAF, Katz G, Takaoka NY, Lebrão ML et al. Óbitos por serpentes peçonhentos no Estado de Sáo Paulo: avaliação de 43 casos, 1988/93. Rev Ass Med Brasil 1998;44(4):312-8.

6. Amorim AM, Carvalho FM, Lira-da-Silva RM, Brazil TK. Acidentes por escorpião em uma área do Nordeste de Amaralina, Salvador, Bahia, Brasil. Rev Soc Bras Med Trop 2003;36(1):51-56.

7. Miranda RC, Gouvêa GM, Rocha PRF, Vasconcelos UMR, Caldeira CAM, Godoy MF. Avaliação clínicoepidemiológica do foneutrismo na regiáo de São José do Rio Preto, São Paulo. HB Científica 2000;7(1):4-10.

8. Divisão de Zoonoses do Centro de Vigilância Epidemiológica de Sáo Paulo [online]. [citado 2006 Set 25]. Disponível em: URL: http:// www.cve.saude. sp.gov.br/

9. Belluomini HE, Wakamatsu CT, Lucas SM, Cardoso JLC. Acidentes do trabalho por animais peçonhentos. Rev Bras Saúde Ocup 1987;15(60):38-42.

10. Amorim AM. Acidentes escorpiônicos em uma área do Nordeste de Amaralina, Salvador-Bahia [tese]. Salvador: Universidade Federal da Bahia; 2001. 109 p. 